\title{
PERAN KOMITMEN ORGANISASIONAL MEMEDIASI PENGARUH KEPEMIMPINAN TRANSFORMASIONAL TERHADAP OCB
}

\author{
I Gede Krisna Pratama ${ }^{1}$ \\ Ni Wayan Mujiati² \\ ${ }^{1,2}$ Fakultas Ekonomi dan Bisnis Universitas Udayana (Unud), Bali, Indonesia \\ email: krisnapratama388@gmail.com
}

\begin{abstract}
ABSTRAK
Tujuan penelitian ini adalah untuk mengetahui pengaruh kepemimpinan transformasional terhadap komitmen organisasional, untuk mengetahui pengaruh kepemimpinan transformasional terhadap $O C B$, untuk mengetahui pengaruh komitmen organisasional terhadap $O C B$, serta untuk mengetahui peran komitmen organisasional dalam memediasi pengaruh kepemimpinan transformasional terhadap $O C B$. Penelitian ini dilakukan pada Dinas Koperasidan UKM Provinsi Bali. Jumlah sampel yang digunakan dalam penelitian ini yaitu 56 orang, dengan menggunakan metode sampel jenuh (sensus), dimana menggunakan keseluruhan populasi sebagai sampel. Data di analisis menggunakan teknikan alisis jalur (Path Analysis). Hasil penelitian menunjukkan bahwa kepemimpinan transformasional berpengaruh positif dan signifikan terhadap komitmen organisasional pada Dinas Koperasi dan UKM Provinsi Bali, kepemimpinan transformasional berpengaruh positif dan signifikan terhadap $O C B$, komitmen organisasional berpengaruh positif dan signifikan terhadap $O C B$, serta komitmen organisasional secara positif dan signifikan memediasi kepemimpinan transformasional terhadap $O C B$ pada Dinas Koperasi dan UKM Provinsi Bali.

Kata Kunci: kepemimpinan transformasional, komitmen organisasional, $O C B$.
\end{abstract}

\begin{abstract}
The purpose of this study was to determine the effect of transformational leadership on organizational commitment, to determine the effect of transformational leadership on $O C B$, to determine the effect of organizational commitment on $O C B$, and to determine the role of organizational commitment in mediating the effect of transformational leadership towards $O C B$ . This research was conducted at the Office of Cooperatives and SMEs in Bali Province. The number of samples used in this study is 56 people, using the saturated sample method (census), which uses the entire population as a sample. Data in analysis uses path analysis technique. The results showed that transformational leadership had a positive and significant effect on organizational commitment at the Bali Provincial Cooperative and SME Office, transformational leadership had a positive and significant effect on OCB, organizational commitment had a positive and significant effect on $O C B$, and organizational commitment positively and significantly mediates transformational leadership towards OCB at the Bali Provincial Cooperative and SME Office.
\end{abstract}

Keywords: transformational leadership, organizational commitment, $O C B$. 


\section{PENDAHULUAN}

Suatu organisasi ketika didirikan telah memiliki visi, misi dan tujuan yang ingin dicapai. Keberhasilan untuk mewujudkan visi, misi, dan tujuan tersebut akan dipegaruhi oleh banyak faktor. Tiga dari banyak faktor yang dapat mempengaruhi keberhasilan perusahaan dalam mencapai tujuan yang telah ditetapkan adalah yang pertama peran dari sumber daya manusia atau SDM yang dimiliki oleh perusahaan. Hal kedua yang dapat mempengaruhi adalah perilaku ekstra atau $O C B$ dan yang ketiga adalah tingkat efektivitas ketika melaksanakan pekerjaan. SDM yang dimiliki oleh perusahaan memiliki peran penting terhadap kemajuan perusahaan itu sendiri, oleh karena itu SDM merupakan aset dari perusahaan yang harus dikelola dengan baik agar memberikan manfaat bagi perusahaan (Mira, 2012).

Karyawan ketika melaksanakan tugasnya dengan baik tanpa adanya paksaan dan bekerja dengan tulus, perilaku tersebut disebut dengan organizational citizenship behavior atau OCB (Suryanatha \& Ardana, 2014). OCB timbul dari diri pekerja itu sendiri dan bukan dari jobdesk yang dimilikinya (Al-Zu'bi, 2011). Ketika organisasi memberikan feedback yang dianggap sesuai oleh pegawai, maka pegawai tersebut akan lebih mungkin berperilaku ekstra.

Organizational citizenship behavior (OCB) merupakan hal yang baik bagi perusahaan dan dapat ditingkatkan dengan memerhatikan beberapa faktor yaitu pertama kepemimpinan transformasional dan yang kedua komitmen organisasional (Maharani et al., 2013). Penelitian-penelitian sebelumnya telah berhasil menemukan adanya hubungan antara faktor-faktor tersebut terhadap OCB (Huang et al., 2012)

Dengan adanya kebijakan dari Gubernur Bali untuk meningkatkan pengembangan pada usaha kecil yang ada di bali, maka Dinas Koperasi dan UKM Provinsi Bali telah mulai melaksanakan berbagai aktivitas untuk mendukung amanat dari Gubernur Bali tersebut. Meski kebanyakan aktivitas pekerjaan Dinas Koperasi dan UKM Provinsi Bali dilakukan di dalam kantor atau ruangan, beberapa aktivitas perlu dilakukan dilapangan atau dilakukan di luar kantor. Kegiatan yang padat ini menuntut para pegawai untuk memiliki niat dalam berperilaku ekstra.

Perilaku ekstra yang diharapkan dimiliki oleh pegawai belum tentu selalu tercapai. Berdasarkan hasil wawancara yang dilakukan tidak adanya perilaku ekstra oleh pegawai muncul sebagai masalah di Dinas Koperasi dan UKM Provinsi Bali. Tidak adanya niat untuk membantu pegawai lain dalam menyelesaikan pekerjaan lebih atau tambahan ketika tugas individu telah terselesaikan, kemampuan pemimpin dalam memenuhi kebutuhan pegawai yang masih kurang hingga interaksi baik antara pegawai dengan atasan maupun dengan antar pegawai yang masih kurang merupakan masalah-masalah yang dihadapi oleh Dinas Koperasi dan UKM Provinsi Bali. Jika masalah-masalah ini dibiarkan dalam jangka panjang akan menyebabkan turunnya efektivitas organisasi dalam melakukan pekerjaan. Pekerjaan dari Dinas Koperasi dan UKM Provinsi Bali adalah memberikan informasi dan pembinaan pada koperasi-koperasi yang ada di Bali, dengan tanggung jawab tersebut diperlukan orang-orang yang memiliki niat dalam berperilaku ekstra.

Berdasarkan observasi yang telah dilakukan, masalah yang ditemukan pada kantor tersebut timbul akibat dari karakteristik yang dimiliki oleh masing-masing 
individu berbeda sehingga inisiatif untuk melakukan pekerjaan maupun membantu rekan kerja tidak sama pada setiap individu, serta kurang intensifnya pemimpin untuk memperhatikan kebutuhan pegawai agar pekerjaan lebih cepat terselesaikan. Peranan pemimpin sangat diperlukan dalam wilayah kantor untuk mendorong pegawai dalam meningkatkan kemampuan di dalam mengambil pekerjaannya.

Rahmatun \& Kistyanto (2014) dan Lian \& Tui (2012) dalam penelitian yang dilakukan menemukan adanya pengaruh yang positif dari gaya kepemimpinan transformasional berpengaruh pada OCB. Pengaruh positif tersebut berarti ketika seorang pemimpin menerapkan gaya kepemimpinan transformasional secara intensif maka pegawai akan lebih mungkin untuk berperilaku OCB. Menurut Robins \& Judge (2008) kepemimpinan transformasional adalah jenis kepemimpinan yang terbaik karena dapat memotivasi para pegawai agar bekerja sesuai dengan tujuan yang belum pernah diraih sebelumnya, memberikan perhatian pada pegawai, mampu melatih, serta membuat pegawai loyal terhadap organisasi. Dengan adanya gaya kepemimpinan transformasional yang sesuai dengan situasi dan kondisi organisasi maka pegawai akan lebih semangat dalam menjalankan tugasdan kewajibannya dalam mengoptimalkan usaha yang lebih memuaskan kearah tercapainya visi dan misi organisasi.

Dasar dari adanya kepemimpinan transformasional adalah sebuah keinginan akan suatu perubahan kearah yang lebih baik. Perubahan ini dapat dicapai dengan lebih memotivasi anggota organisasi, memberikan inspirasi, stimulasi serta memberikan perhatian pada anggota organisasi (Karim \& Rehman, 2012). Kepemimpinan transformasional adalah kepemimpinan yang peka terhadap perubahan yang terjadi di lingkungan sekitar serta mampu untuk melakukan perubahan kearah pengembangan organisasi.

Priansa (2014) menyatakan sauatu loyalitas terhadap organisasi,rasa memiliki oleh anggota organisasi dan keinginan untuk selalu terlibat dalam upaya memajukan organisasi merupakan yang disebut dengan komitmen organisasional. Menurut Griffin (2008), komitmen organisasional adalah sikap yang mencerminkan sejauh mana seorang individu mengenal dan terikat pada organisasinya. Pekerja yang memiliki komitmen organisasional yang tinggi akan lebih berorientasi pada kerja, cenderung senang membantu dan dapat bekerjasama.

Foote \& Tang (2008), menemukan bahwa komitmen organisasional berpengaruh pada Organizatonal Citizenship Behavior (OCB). Sesen \& Basim (2012), menyatakan bahwa ketika karyawan memiliki komitmen organisasional yang tinggi, maka secara otomatis mereka akan rela melakukan OCB. Komitmen organisasional pada pegawai tersebut yang menjadi pendorong dalam terciptanya Organizational Citizenship Behavior yang penting untuk produktivitas dan kinerja bagi organisasi. (Ortiz et al., 2015), menemukan hasil bahwa komitmen organisasional memiliki pengaruh yang positif terhadap OCB.

Peran komitmen organisasional memediasi pengaruh kepemimpinan transformasional terhadap $O C B$ dapat dilihat darihasil penelitian yang dilakukan oleh Yang (2012), komitmen organisasional memediasi pengaruh kepemimpinan transformasional pada $O C B$. Kaihatu \& Rini (2007) dalam penelitiannya menemukan adanya hubungan antara kepemimpinan transformasional terhadap $O C B$. 
Penelitian ini dilandasi oleh Teori Pertukaran Sosial atau Social Exchange Theory. Teori ini pertama kali ditemukan oleh Blau pada tahun 1964. OCB sering dijelaskan dengan menggunakan teori pertukaran social. Perilaku OCB akan terwujud ketika pegawai merasakan suatu pengaruh positif terhadap dirinya ketika bekerja di suatu organisasi. Perilaku OCB merupakan salah satu feedback yang diberikan oleh pegawai kepada organisasi karena pengaruh positif yang dirasakan oleh pegawai tersebut.

Ketika individu memiliki keinginan untuk membuat reputasi organisasi tempat dia bekerja dan bersedua berperilaku OCB maka individu tersebut merasa dengan berperilaku OCB maka ada nilai-nilai positif yang akan didapatkan oleh individu tersebut. Hubungan ini dijelaskan oleh teori pertukaran social (Chiang \& Hsieh, 2012). Pertukaran sosial dapat terjadi ketika pegawai dan organisasi dapat memberikan suatu hal yang didasari pada kepercayaan melalui komitmen organisasional pada karyawan/ pegawai (Fung et al., 2012).

Karyawan ketika melaksanakan tugasnya dengan baik tanpa adanya paksaan dan bekerja dengan tulus, perilaku tersebut disebut dengan organizational citizenship behavior atau OCB (Suryanatha \& Ardana, 2014). OCB timbul dari diri pekerja itu sendiri dan bukan dari jobdesk yang dimilikinya (Al-Zu'bi, 2011). Ketika organisasi memberikan feedback yang dianggap sesuai oleh pegawai, maka pegawai tersebut akan lebih mungkin berperilaku ekstra. Kumar et al. (2009) berpendapat bahwa OCB merupakan suatu tindakan yang dilakukan oleh individu yang berdampak pada efektivitas organisasi dan memiliki hubungan dengan sistem imbalan yang disusun oleh organisasi tersebut. Perilaku OCB yang dilakukan pegawai dapat dilihat ketika pegawai bertindak tanpa adanya paksaan dan tanpa adanya harapan untuk mendapat imbalan dari organisasi dan tindakan tersebut memberi manfaat yang positif bagi organisasi (Shweta \& Srirang, 2010).

Kepemimpinan transformasional merupakan kemampuan individu untuk mempengaruhi, memotivasi dan memungkinkan pengikut untuk memberikan kontribusi terhadap efektivitas dan kesuksesan organisasi (Suyitno \& Utomo., 2017). Dasar dari adanya kepemimpinan transformasional adalah sebuah keinginan akan suatu perubahan kearah yang lebih baik. Perubahan ini dapat dicapai dengan lebih memotivasi anggota organisasi, memberikan inspirasi, stimulasi serta memberikan perhatian pada anggota organisasi (Karim \& Rehman, 2012). Kepemimpinan transformasional merupakan suatu perilaku pemimpin yang memberikan perhatian kepada karyawannya, rangsangan intelektual serta nilai moral kepada para bawahannya untuk meningkatkan kesadaran individu (Rorimpandey, 2013).

Ketika pegawai menununjukan loyalitas terhadap organisasi serta memiliki pendirian yang tetep untuk bekerja keras dan selalu menjalankan tugas dan pekerjaan dengan baik demi kemajuan perusahaan, hal tersebut disebut dengan komitmen organisasional (Luthans \& Frens, 2006). Taner et al. (2015), Faharani, Taghadosi, \& Behboudi (2011), Lee (2010), Ismail et al. (2011), dan Suryaningsih et al. (2017) dalam penelitian-penelitian yang dilakukan yang mengangkat topik serupa menemukan bahwa terdapat hubungan yang positif antara kepemimpinan transformasional pada komitmen organisasional.

$\mathrm{H}_{1}$ : Gaya kepemimpinan transformasional berpengaruh positif dan signifikan 
terhadap komitmen organisasional.

Kepemimpinan transformasional merupakan kemampuan individu untuk mempengaruhi, memotivasi dan memungkinkan pengikut untuk memberikan kontribusi terhadap efektivitas dan kesuksesan organisasi (Suyitno \& Utomo., 2017). Dasar dari adanya kepemimpinan transformasional adalah sebuah keinginan akan suatu perubahan kearah yang lebih baik. Perubahan ini dapat dicapai dengan lebih memotivasi anggota organisasi, memberikan inspirasi, stimulasi serta memberikan perhatian pada anggota organisasi (Karim \& Rehman, 2012). Karyawan ketika melaksanakan tugasnya dengan baik tanpa adanya paksaan dan bekerja dengan tulus, perilaku tersebut disebut dengan organizational citizenship behavior atau OCB (Suryanatha \& Ardana, 2014). OCB timbul dari diri pekerja itu sendiri dan bukan dari jobdesk yang dimilikinya (Al-Zu'bi, 2011). Ketika organisasi memberikan feedback yang dianggap sesuai oleh pegawai, maka pegawai tersebut akan lebih mungkin berperilaku ekstra.

Malik, Saleem, \& Naheem (2016), Yohana (2017), Lian \& Tui (2012), Zabihi \& Hashemzehi (2012), Rahmi (2014) dalam penelitian-penelitian yang dilakukan dengan menggunakan variabel yang sama menemukan adanya hubungan positif dari kepemimpinan transformasional pada OCB.

$\mathrm{H}_{2}$ : Gaya kepemimpinan transformasional berpengaruh positif dan signifikan terhadap $O C B$.

Karyawan ketika melaksanakan tugasnya dengan baik tanpa adanya paksaan dan bekerja dengan tulus, perilaku tersebut disebut dengan organizational citizenship behavior atau OCB (Suryanatha \& Ardana, 2014). OCB timbul dari diri pekerja itu sendiri dan bukan dari jobdesk yang dimilikinya (Al-Zu'bi, 2011). Ketika organisasi memberikan feedback yang dianggap sesuai oleh pegawai, maka pegawai tersebut akan lebih mungkin berperilaku ekstra. Kumar et al. (2009) berpendapat bahwa OCB merupakan suatu tindakan yang dilakukan oleh individu yang berdampak pada efektivitas organisasi dan memiliki hubungan dengan sistem imbalan yang disusun oleh organisasi tersebut. Perilaku OCB yang dilakukan pegawai dapat dilihat ketika pegawai bertindak tanpa adanya paksaan dan tanpa adanya harapan untuk mendapat imbalan dari organisasi dan tindakan tersebut memberi manfaat yang positif bagi organisasi (Shweta \& Srirang, 2010).

Penelitian yang dilakukan oleh Sani (2013), Sahertian \& Soetjipto (2011), Han et al. (2016), Suparta et al. (2013), dan Bakan et al. (2013) menemukan hasil yang sama yaitu ditemukan adanya hubungan positif antara variabel komitmen organisasional terhadap OCB.

$\mathrm{H}_{3}$ : Komitmen organisasional berpengaruh positif dan signifikan terhadap Organizational Citizenship Behavior(OCB).

Kepemimpinan transformasional merupakan kemampuan individu untuk mempengaruhi, memotivasi dan memungkinkan pengikut untuk memberikan kontribusi terhadap efektivitas dan kesuksesan organisasi (Suyitno \& Utomo, 2017). Dasar dari adanya kepemimpinan transformasional adalah sebuah keinginan akan suatu perubahan kearah yang lebih baik. Perubahan ini dapat dicapai dengan lebih memotivasi anggota organisasi, memberikan inspirasi, stimulasi serta memberikan perhatian pada anggota organisasi (Karim \& Rehman, 2012). Pegawai menjadi termotivasi dan menjadi percaya, kagum, hormat serta setia kepada 
pemimpinnya. Kepemimpinan transformasional merupakan suatu perilaku pemimpin yang memberikan perhatian kepada karyawannya, rangsangan intelektual serta nilai moral kepada para bawahannya untuk meningkatkan kesadaran individu (Rorimpandey, 2013). Truckenbrodt (2000), Wang (2006), Chi et al. (2007), Kaihatu \& Rini (2007), Lamidi (2008) dalam penelitian yang dilakukan, berhasil menemukan adanya pengaruh dari kepemimpinan transformasional pada OCB.

$\mathrm{H}_{4}$ : Komitmen Organisasional memediasi hubungan gaya kepemimpinan transformasional terhadap $O C B$.

\section{METODE PENELITIAN}

Lokasi penelitian ini adalah Dinas Koperasi dan UKM Provinsi Bali, yang beralamat di Jalan D. I Panjaitan-Renon, Denpasar. Alasan memilih lokasi pada Dinas ini karena memiliki pegawai yang cukup banyak dengan tugas dan tanggung jawab yang berbeda-beda. Obyek dari penelitian ini adalah komitmen organisasional, kepemimpinan transformasional dan $O C B$.Definisi operasional variabel adalah suatu definisi yang diberikan kepada variabel, dengan tujuan untuk memberi arti atau menspesifikasikannya. Definisi operasional dalam penelitian ini sebagai berikut.OCB adalah suatu tindakan yang dilakukansecara sukarela oleh seseorang dengan bersedia membantu rekan kerja serta melakukan suatu pekerjaan melebihi tugas-tugas dan tanggung jawabnya. Menurut Organ, Podsakoff, \& MacKenzie (2006), terdapat 5 indikator dari OCB, sebagai berikut.

Altruism. Merupakan inisiatif pegawai untuk menolong pegawai lain dalam organisasi tanpa ada paksaan atau secara suka rela. Indikator ini diukur dari persepsi responden mengenai bersedia membantu rekan kerja yang memiliki beban kerja lebih dengan sukarela.Civic virtue. Merupakan perilaku yang menunjukan bahwa seseorang pegawai melakukan pastisipasi secara sukarela terhadap kegiatan dalam organisasi. Indikator ini dapat diukur dari persepsi responden berpartisipasi secara sukarela dalam setiap kegiatan organisasi.Conscientiousness. Merupakan perilaku pegawai yang berkeinginan untuk melebihi standar pencapaian. Indikator ini dapat diukur dari persepsi responden yang bersedia melaksanakan tugas melebihi tugas yang diberikan. Courtesy. Merupakan perilaku yang mampu meringankan masalahmasalah yang berkaitan dengan pekerjaan yang dihadapi sesama pegawai. Indikator ini dapat diukur dari persepsi responden mengenai kesediaanya meringankan masalah-masalah yang berkaitan dengan pekerjaan yang dihadapi sesama pegawai. Sportmanship. Merupakan pegawai tidak membuat isu yang dapat menjatuhkan pegawai lain. Indikator ini dapat diukur dari persepsi responden mengenai tidak memberikan isu-isu yang dapat menjatuhkan pegawai lain.

Kepemimpinan transformasional adalah kemampuan yang dimiliki individu untuk mempengaruhi, menimbulkan rasa bangga, mampu memberikan dorongan serta mampu meningkatkan kemampuan yang dimiliki bawahannya demi pencapaian tujuan dari suatu organisasi. Menurut Bass, Avolio, Jung, \& Berson (2003), terdapat 4 indikator dari kepemimpinan transformasional, sebagai berikut.Pengaruh idealis (Idealized influence). Merupakan kemampuan pemimpin yang dapat memunculkan rasa bangga pegawainya. Indikator ini dapat diukur melalui persepsi responden mengenai kemampuan pemimpin membuat bawahanya 
bangga karena memiliki pendirian yang kuat dalam memimpin organisasi. Motivasi inspiratif (Motivation inspirational). Merupakan kemampuan pemimpin dalam memberikan dorongan untuk pegawainya. Indikator ini dapat diukur melalui persepsi responden mengenai kemampuan pemimpin dalam memberikan dorongan agar pegawai semangat dalam bekerja. Stimulasi individu (individual stimulation). Merupakan kemampuan pemimpin menstimulasi usaha bawahannya untuk berlaku inovatif dan kreatif dalam bekerja. Indikator ini dapat diukur melalui persepsi responden mengenai usaha pemimpin untuk dapat merangsang kreatifitas bawahan dalam melakukan pekerjaan. Pertimbangan individual (Individual consideration). Merupakan kemampuan pemimpin transformasional dalam memberikan perhatian khusus pada kebutuhan setiap individu untuk berprestasi dan berkembang. Indikator ini dapat diukur melalui persepsi responden mengenai kemampuan pemimpin untuk memperhatikan kebutuhan bawahan.Komitmen organisaional merupakan sikap yang menunjukan loyalitas dan merupakan proses bagaimana seorang pegawai mengekpresikan perhatiannya kepada kesuksesan dan pencapaian tujuan dari organisasinya.

Menurut Meyer \& Allen (1991), terdapat 3 indikator dari komitmen organisasional, sebgai berikut. Komitmen afektif (Affective commitment). Merupakan hubungan emosional pegawai organisasi terhadap kegiatan organisasinya. Indikator ini dapat diukur dari persepsi responden atas keterlibatan emosional terhadap orgnisasinya. Komitmen berkelanjutan (Continuance commitment). Merupakan kesadaran pegawai organisasi jika meninggalkan organisasi maka akan mengalami kerugian. Indikator ini dapat diukur dari persepsi responden atas resiko yang didapatkan ketika meninggalkan organisasi. Komitmen normatif (Normative commitment). Merupakan perasaan pegawai yang menggambarkan keterikatan untuk terus berada dalam organisasi. Indikator ini dapat diukur dari persepsi responden terhadap keterlibatan seorang pegawai dalam bekerja demi kepentingan organisasi. Populasi yang digunakan dalam penelitian ini adalah seluruh pegawai PNS yang bekerja pada Dinas Dinas Koperasi dan UKM Provinsi Bali berjumlah 56 orang. Data jumlah pegawai pada Dinas Koperasi dan UKM Provinsi Bali tahun 2018 ditunjukan pada Tabel 1.

\section{Tabel 1.}

Data Jumlah Pegawai PNS Pada Dinas Koperasi dan UKM Provinsi Bali Tahun 2018

\begin{tabular}{|c|c|c|}
\hline No. & Jabatan & $\begin{array}{c}\text { Jumlah Pegawai } \\
\text { (Orang) }\end{array}$ \\
\hline 1. & Pejabat Eselon III & 6 \\
\hline 2. & Pejabat Eselon IV & 18 \\
\hline 3. & Staf & 30 \\
\hline 4. & Fungsional & 2 \\
\hline Total & & 56 \\
\hline
\end{tabular}

Sumber : Dinas Koperasi dan UMKM Provinsi Bali, 2018

Teknik sampel yang digunakan dalam penelitian ini adalah sampel jenuh. Hal ini dikarenakan populasi yang digunakan pada penelitian ini relatif kecil, kurang 
dari 100 orang atau penelitian yang ingin membuat generalisasi dengan kesalahan yang sangat kecil. Berdasarkan uraian diatas, besarnya sampel yang diteliti berjumlah 56 orang karyawan/ pegawai PNS pada Dinas Koperasi dan UKM Provinsi Bali.

Menggunakan dua jenis data yaitu yang pertama adalah data primer dimana data ini bersumber dari instrumen penelitian ini yaitu kuesioner. Untuk data yang kedua yaitu data sekunder dimana bersumber dari arsip dan informasi yang didapat dari hasil observasi. Metode pengumpulan data yang digunakan adalah kuesioner, observasi, dan wawancara.

\section{HASIL DAN PEMBAHASAN}

Uji validitas bertujuan untuk memeriksa apakah kuesioner sebagai instrumen penelitian sudah tepat untuk mengukur apa yang seharusnya diukur. Suatu instrumen dikatakan valid apabila memiliki koefisien korelasi antara butir dengan skor total dalam instrumen tersebut lebih besar dari 0,30 dengan tingkat kesalahan Alpha 0,05. Tabel 2 menunjukkan bahwa seluruh instrumen penelitian yang digunakan untuk mengukur variabel Organizational Citizenship Behavior, kepemimpinan transformasional dan komitmen organisasional memiliki nilai koefisien korelasi dengan skor total seluruh item pernyataan lebih besar dari 0,30 dengan signifikansi kurang dari 0,05 . Hal ini menunjukkan bahwa butir-butir pernyataan dalam instrumen penelitian tersebut valid dan layak digunakan sebagai instrumen penelitian.

Tabel 2.

Rekapitulasi Hasil Uji Validitas Instrumen Penelitian

\begin{tabular}{ccccc}
\hline Variabel & Indikator & $\begin{array}{c}\text { Koefisien } \\
\text { Korelasi }\end{array}$ & Sig. (2-tailed) & Keterangan \\
\hline Organizational & Y1 & 0,754 & 0,000 & Valid \\
Citizenship Behavior & Y2 & 0,713 & 0,000 & Valid \\
(Y) & Y3 & 0,829 & 0,000 & Valid \\
& Y4 & 0,598 & 0,000 & Valid \\
& Y5 & 0,821 & 0,000 & Valid \\
Kepemimpinan & X1 & 0,790 & 0,000 & Valid \\
Transformasional (X) & X2 & 0,756 & 0,000 & Valid \\
& X3 & 0,774 & 0,000 & Valid \\
Komitmen & X4 & 0,759 & 0,000 & Valid \\
Organisasional (M) & M1 & 0,788 & 0,000 & Valid \\
& M2 & 0,898 & 0,000 & Valid \\
& M3 & 0,840 & 0,000 & Valid \\
\hline
\end{tabular}

Sumber: Data diolah, 2019

Didapatkan nilai koefisien korelasi dengan skor total seluruh item pernyataan melebihi dari 0,30 dengan signifikansi kurang dari 0,05. Hasil tersebut memiliki arti setiap butir pertanyaan dalam kuesioner yang digunakan dalam penelitian dinyatan valid. 
Reliabilitas menunjukkan sejauh mana suatu pengukuran dapat menghasilkan data yang sama (konsisten) bila dilakukan pengukuran beberapa kali terhadap obyek yang sama. Walaupun instrumen yang valid umumnya pasti reliabel, tetapi pengujian reliabilitas instrumen perlu dilakukan karena reliabilitas instrumen merupakan syarat untuk pengujian validitas instrumen (Sugiyono, 2014:122). Suatu variabel dikatakan reliabel jika memberikan nilai Cronbach alpha $(\alpha)>0,60$ (Ghozali, 2012:46).

Tabel 3.

Rekapitulasi Hasil Uji Reliabilitas Instrumen Penelitian

\begin{tabular}{clcc}
\hline No & \multicolumn{1}{c}{ Variabel } & $\begin{array}{c}\text { Cronbach's } \\
\text { Alpha }\end{array}$ & Keterangan \\
\hline 1. & Organizational Citizenship Behavior $(\mathrm{Y})$ & 0,796 & Reliabel \\
2. & Kepemimpinan Transformasional $(\mathrm{X})$ & 0,755 & Reliabel \\
3. & Komitmen Organisasional $(\mathrm{M})$ & 0,773 & Reliabel \\
\hline
\end{tabular}
Sumber: Data diolah, 2019

Tabel 3. menunjukkan bahwa seluruh instrumen penelitian memiliki koefisien Cronbach's Alpha lebih dari 0,60. Jadi dapat dinyatakan bahwa seluruh variabel telah memenuhi syarat reliabilitas atau kehandalan sehingga dapat digunakan untuk melakukan penelitian.

Pengumpulan data melalui kuesioner terdiri atas pernyataan responden berdasarkan masing-masing variabel, yaitu $O C B$, kepemimpinan transformasional, dan komitmen organisasional. Penilaian responden mengenai variabel-variabel dalam penelitian perlu dilakukan penentuan skor dengan nilai tertinggi maksimal 5 dan terendah minimal 1 , sehingga dapat disusun kriteria pengukuran dilihat pada Tabel 4.

Tabel 4.

Kriteria Pengukuran Deskripsi Variabel Penelitian

\begin{tabular}{ccc}
\hline Skala Pengukuran & $\begin{array}{c}\text { Katagori Penilaian Variabel } \\
\text { Kepemimpinan } \\
\text { Transformasional }\end{array}$ & $\begin{array}{c}\text { Katagori Penilaian } \\
\text { Variabel Komitmen } \\
\text { Organisasional dan OCB }\end{array}$ \\
\hline $1,00-1,79$ & Sangat tidak baik & Sangat rendah \\
$1,80-2,59$ & Tidak baik & Rendah \\
$2,60-3,39$ & Kurang baik & Cukup \\
$3,40-4,19$ & Baik & Tinggi \\
$4,20-5,00$ & Sangat Baik & Sangat Tinggi \\
\hline
\end{tabular}

Sumber: Data diolah, 2019

Variabel OCB diukur dengan menggunakan 5 item pernyataan yang berhubungan dengan niat karyawan dalam membantu rekan kerja serta bekerja melebihi tugas-tugas yang diberikan. Jawaban responden mengenai masing-masing pernyataan pada variabel OCB secara rinci dapat dilihat pada Tabel 5.

Jawaban reponden pada variabel OCB pada Tabel 5 secara keseluruhan memiliki rata-rata sebesar 3,83 yang berarti niat karyawan untuk membantu rekan kerja dan bekerja melebihi tugas-tugas yang diberikan tergolong dalam kriteria tinggi, namun pernyataan tentang "Saya bersedia melaksanakan tugas melebihi 
tugas yang diberikan" memiliki nilai rata-rata terendah dibandingkan pernyataan yang lain yaitu sebesar 3,34, ini berarti niat pegawai dalam melaksanakan tugas melebihi tugas yang diberikan harus ditingkatkan lagi, seharusnya organisasi mampu membangkitkan semangat pegawai agar mampu bekerja melebihi harapan.

Tabel 5.

Deskripsi Variabel Organizational Citizenship Behavior (Y)

\begin{tabular}{|c|c|c|c|c|c|c|c|c|c|}
\hline \multirow{2}{*}{ No. } & \multirow{2}{*}{ Pernyataan } & \multicolumn{5}{|c|}{ Skor Jawaban } & \multirow{2}{*}{$\begin{array}{c}\text { Jumlah } \\
\text { Skor }\end{array}$} & \multirow{2}{*}{$\begin{array}{l}\text { Rata- } \\
\text { Rata }\end{array}$} & \multirow{2}{*}{ Kriteria } \\
\hline & & STS & TS & $\mathbf{N}$ & $\mathbf{S}$ & SS & & & \\
\hline 1. & $\begin{array}{l}\text { Saya bersedia } \\
\text { membantu rekan kerja } \\
\text { yang memiliki beban } \\
\text { kerja lebih dengan } \\
\text { sukarela. }\end{array}$ & 1 & 3 & 6 & 32 & 14 & 222 & 3,96 & Tinggi \\
\hline 2. & $\begin{array}{l}\text { Saya bersedia } \\
\text { berpartisipasi secara } \\
\text { suka rela dalam setiap } \\
\text { kegiatan perusahaan }\end{array}$ & 1 & 2 & 6 & 43 & 4 & 214 & 3,82 & Tinggi \\
\hline 3. & $\begin{array}{l}\text { Saya bersedia } \\
\text { melaksanakan tugas } \\
\text { melebihi tugas yang } \\
\text { diberikan }\end{array}$ & 1 & 10 & 15 & 28 & 2 & 187 & 3,34 & Cukup \\
\hline 4. & $\begin{array}{l}\text { Saya bersedia } \\
\text { meringankan masalah- } \\
\text { masalah yang berkaitan } \\
\text { dengan pekerjaan yang } \\
\text { dihadapi sesama } \\
\text { karyawan }\end{array}$ & 1 & 2 & 9 & 35 & 9 & 216 & 3,86 & Tinggi \\
\hline 5. & $\begin{array}{l}\text { Saya tidak memberikan } \\
\text { isu - isu yang dapat } \\
\text { menjatuhkan karyawan } \\
\text { lain }\end{array}$ & 1 & 2 & 3 & 30 & 20 & 233 & 4,16 & Tinggi \\
\hline \multicolumn{7}{|c|}{ Rata-rata } & & 3,83 & Tinggi \\
\hline
\end{tabular}

Variabel kepemimpinan transformasional diukur dengan menggunakan 4 item pernyataan yang berhubungan dengan kemampuan pemimpin dalam mempengaruhi bawahannya agar mampu mencapai tujuan perusahaan. Jawaban responden mengenai masing-masing pernyataan pada variabel kepemimpinan transformasional secara rinci dapat dilihat pada Tabel 6.

Jawaban responden pada variabel kepemimpinan transformasional pada Tabel 6. secara keseluruhan memiliki rata-rata sebesar 4,30 yang berarti kemampuan pemimpin dalam mempengaruhi bawahannya agar mampu mencapai tujuan perusahaan tergolong dalam kriteria sangat baik, namun pernyataan tentang "Pemimpin mampu untuk memperhatikan kebutuhan bawahan" perlu diterapkan lebih baik lagi karena memiliki nilai rata-rata terendah dibandingkan pernyataan yang lain yaitu sebesar 4,09, ini berarti pemimpin kurang memperhatikan kebutuhan bawahan dalam mendukung pekerjaannya dan seharusnya pemimpin yang menggunakan gaya kepemimpinan transformasional sewaktu - waktu harus mendampingi bawahan dalam bekerja. 
Tabel 6.

Deskripsi Variabel Kepemiminan Transformasional (X)

\begin{tabular}{|c|c|c|c|c|c|c|c|c|c|}
\hline \multirow{2}{*}{ No. } & \multirow{2}{*}{ Pernyataan } & \multicolumn{5}{|c|}{ Skor Jawaban } & \multirow{2}{*}{$\begin{array}{l}\text { Jumlah } \\
\text { Skor }\end{array}$} & \multirow{2}{*}{$\begin{array}{l}\text { Rata- } \\
\text { Rata }\end{array}$} & \multirow{2}{*}{ Kriteria } \\
\hline & & STS & TS & $\mathbf{N}$ & $\mathbf{S}$ & SS & & & \\
\hline 1. & $\begin{array}{l}\text { Pemimpin mampu } \\
\text { membuat bawahannya } \\
\text { bangga karena memiliki } \\
\text { pendirian yang kuat } \\
\text { dalam memimpin } \\
\text { organisasi. }\end{array}$ & 1 & 2 & 2 & 22 & 29 & 243 & 4,34 & $\begin{array}{l}\text { Sangat } \\
\text { Baik }\end{array}$ \\
\hline 2. & $\begin{array}{l}\text { Pemimpin mampu } \\
\text { memberikan dorongan } \\
\text { kepada pegawai agar } \\
\text { semangat dalam bekerja. }\end{array}$ & 1 & 2 & 1 & 22 & 30 & 245 & 4,38 & $\begin{array}{l}\text { Sangat } \\
\text { Baik }\end{array}$ \\
\hline 3. & $\begin{array}{l}\text { Pemimpin mampu untuk } \\
\text { dapat menumbuhkan } \\
\text { kreatifitas bawahan } \\
\text { dalam melakukan } \\
\text { pekerjaan. }\end{array}$ & 1 & 2 & 1 & 20 & 32 & 247 & 4,41 & $\begin{array}{l}\text { Sangat } \\
\text { Baik }\end{array}$ \\
\hline 4. & $\begin{array}{l}\text { Pemimpin mampu untuk } \\
\text { memperhatikan } \\
\text { kebutuhan bawahan. }\end{array}$ & 2 & 3 & 3 & 26 & 22 & 229 & 4,09 & Baik \\
\hline \multicolumn{7}{|c|}{ Rata-rata } & & 4,30 & $\begin{array}{c}\text { Sangat } \\
\text { Baik }\end{array}$ \\
\hline
\end{tabular}

Jawaban responden pada variabel kepemimpinan transformasional pada Tabel 6. secara keseluruhan memiliki rata-rata sebesar 4,30 yang berarti kemampuan pemimpin dalam mempengaruhi bawahannya agar mampu mencapai tujuan perusahaan tergolong dalam kriteria sangat baik, namun pernyataan tentang "Pemimpin mampu untuk memperhatikan kebutuhan bawahan" perlu diterapkan lebih baik lagi karena memiliki nilai rata-rata terendah dibandingkan pernyataan yang lain yaitu sebesar 4,09.

Tabel 7.

Deskripsi Variabel Komitmen Organisasional (M)

\begin{tabular}{|c|c|c|c|c|c|c|c|c|c|}
\hline \multirow{2}{*}{ No. } & \multirow{2}{*}{ Pernyataan } & \multicolumn{5}{|c|}{ Skor Jawaban } & \multirow{2}{*}{$\begin{array}{c}\text { Jumlah } \\
\text { Skor }\end{array}$} & \multirow{2}{*}{$\begin{array}{l}\text { Rata- } \\
\text { Rata }\end{array}$} & \multirow{2}{*}{ Kriteria } \\
\hline & & STS & TS & $\mathbf{N}$ & $\mathbf{S}$ & SS & & & \\
\hline 1. & $\begin{array}{l}\text { Saya merasa terikat } \\
\text { secara emosional } \\
\text { dengan organisasi }\end{array}$ & 3 & 12 & 10 & 25 & 6 & 184 & 3,29 & Cukup \\
\hline 2. & $\begin{array}{l}\text { Saya merasa } \\
\text { kehidupannya akan } \\
\text { terganggu apabila } \\
\text { meninggalkan } \\
\text { organisasi }\end{array}$ & 1 & 20 & 15 & 12 & 8 & 173 & 3,09 & Cukup \\
\hline 3. & $\begin{array}{l}\text { Saya bersedia } \\
\text { dilibatkan dalam } \\
\text { kegiatan kerja demi } \\
\text { kepentingan organisasi }\end{array}$ & 1 & 2 & 6 & 38 & 9 & 219 & 3,91 & Tinggi \\
\hline \multicolumn{7}{|c|}{ Rata-rata } & & 3,43 & Tinggi \\
\hline
\end{tabular}


Jawaban reponden pada variabel komitmen organisasional pada Tabel 7 . secara keseluruhan memiliki rata-rata sebesar 3,43 yang berarti "saya bersedia dilibatkan dalam kegiatan kerja demi kepentingan organisasi" tersebut tergolong dalam kriteria tinggi, namun pernyataan tentang "saya merasa kehidupannya akan terganggu apabila meninggalkan organisasi" memiliki nilai rata-rata terendah dibandingkan pernyataan yang lain yaitu sebesar 3,09 yang berarti organisasi harus mampu menumbuhkan minat pegawai untuk tetap bekerja pada organisasi.

Tabel 8.

Hasil Uji Normalitas Struktur 1

\begin{tabular}{lc}
\hline & Unstandardized Residual \\
\hline $\mathrm{N}$ & 56 \\
Kolmogorov-Smirnov $Z$ & 0,715 \\
Asymp.Sig.(2-tailed) & 0,686 \\
\hline
\end{tabular}

Setelah dilakukan uji normalitas pada struktur 1 didapatkan hasil yaitu nilai Kolmogorov Sminarnov 0,715. Nilai Asymp. Sig. (2-tailed) dari hasil perhitungan uji normalitas untuk struktur 1 adalah 0,686 . Hasil yang didapat memiliki arti bahwa model persamaan yang digunakan telah berdistribusi normal.

Tabel 9.

Uji Normalitas Struktur 2

\begin{tabular}{lc}
\hline & Unstandardized Residual \\
\hline $\mathrm{N}$ & 56 \\
Kolmogorov-Smirnov $Z$ & 0,716 \\
Asymp.Sig.(2-tailed) & 0,685 \\
\hline
\end{tabular}

Sumber: Data diolah, 2019

Setelah dilakukan uji normalitas pada struktur 2 didapatkan hasil yaitu nilai Kolmogorov Sminarnov 0,716. Nilai Asymp. Sig. (2-tailed) dari hasil perhitungan uji normalitas untuk struktur 2 adalah 0,685 . Hasil yang didapat memiliki arti bahwa model persamaan yang digunakan telah berdistribusi normal.

Tabel 10.

Hasil Uji Multikolinearitas

\begin{tabular}{lcc}
\hline \multicolumn{1}{c}{ Variabel } & Tolerance & VIF \\
\hline Kepemimpinan Transformasional & 0,681 & 1,468 \\
Komitmen Organisasional & 0,681 & 1,468 \\
\hline
\end{tabular}

Sumber: Data diolah, 2019

Setelah dilkukan uji multikolinearitas, didapatkan hasil pada masig masing variabel memiliki nilai tolerance yang melebihi $10 \%$ dan juga memiliki nilai VIF yang kurang dari 10. Hasil tersebut menunjukan bahwa model persamaan regresi yang digunakan dalam penelitian terbebas dari masalah multikolinearitas. 
Uji heteroskedastisitas bertujuan untuk mengetahui apakah dalam model regresi terjadi ketidaksamaan varians dari residual satu pengamatan ke pengamatan yang lain dan pengujian ini dilakukan dengan uji Glejser. Jika nilai signifikansinya di atas 0,05 maka tidak mengandung gejala heteroskedastisitas. Uji heteroskedastisitas untuk penelitian ini akan dijabarkan pada Tabel 11. dan Tabel 12. berikut.

Tabel 11.

Hasil Uji Heteroskedastisitas Struktur 1

\begin{tabular}{|c|c|c|c|c|c|}
\hline \multirow[b]{2}{*}{ Model } & \multicolumn{2}{|c|}{$\begin{array}{c} \\
\text { Unstandardize } \\
\text { d Coefficients } \\
\text { Std. }\end{array}$} & \multirow{2}{*}{$\begin{array}{c}\text { Standardize } \\
\text { d } \\
\text { Coefficients } \\
\text { Beta }\end{array}$} & \multirow{3}{*}{$\frac{\mathbf{T}}{2.611}$} & \multirow{3}{*}{$\frac{\text { Sig. }}{0.012}$} \\
\hline & B & $\begin{array}{l}\text { Std. } \\
\text { Error }\end{array}$ & & & \\
\hline $1 \quad$ (Constant) & 0.603 & 0.231 & & & \\
\hline Kepemimpinan Transformasional & -0.56 & 0.052 & -0.143 & -1.060 & 0.294 \\
\hline
\end{tabular}

Sumber: Data diolah, 2019

Setlah dilakukan uji heteroskedastisitas didapatkan bahwa nilai signifikansi dari variabel kepemimpinan transformasional adalah sebesar 0,294 dimana angka tersebut telah melebihi 0,05. Dari hasil tersebut dapat disimpulkan bahwa model yang digunakan terbebas dari masalah heteroskedastisitas

Tabel 12.

Hasil Uji Heteroskedastisitas Struktur 2

\begin{tabular}{|c|c|c|c|c|c|}
\hline \multirow[b]{2}{*}{ Model } & \multicolumn{2}{|c|}{$\begin{array}{r}\text { Unstandardize } \\
\text { d Coefficients } \\
\text { Std. }\end{array}$} & \multirow[t]{2}{*}{$\begin{array}{c}\text { Standardize } \\
\text { d } \\
\text { Coefficients } \\
\text { Beta }\end{array}$} & \multirow[b]{2}{*}{$\mathbf{T}$} & \multirow[b]{2}{*}{ Sig. } \\
\hline & B & Error & & & \\
\hline $1 \quad$ (Constant) & 0.914 & 0.207 & & 4.408 & 0.000 \\
\hline Kepemimpinan Transformasional & -0.093 & 0.055 & -0.265 & -1.698 & 0.095 \\
\hline Komitmen Organisasional & $-0,044$ & 0.055 & -0.126 & -0.806 & 0.424 \\
\hline
\end{tabular}

Sumber: Data diolah, 2019

Setelah dilakukan uji heteroskedastisitas didapatkan bahwa nilai signifikansi dari variabel kepemimpinan transformasional adalah sebesar 0,095 dan nilai signifikansi untuk variabel komitmen organisasional didapatkan nilai sebesar 0,424. Dari hasil tersebut dapat disimpulkan bahwa model yang digunakan terbebas dari masalah heteroskedastisitas.

Analisis jalur atau Path Analysis merupakan teknik yang digunakan dalam penelitian ini. Hasil perhitungan analisis jalur dengan menggunakan SPSS adalah sebagai berikut.Hasil analisis jalur substruktur 1 seperti yang disajikan pada Tabel 4.16, maka dapat dibuat persamaan struktural sebagai berikut.

$$
\begin{aligned}
& \mathrm{M}=\beta_{1} \mathrm{X}+\mathrm{e}_{1} \ldots \ldots \\
& \mathrm{M}=0,564 \mathrm{X}+\mathrm{e}_{1}
\end{aligned}
$$


Tabel 13.

Hasil Analisis Jalur 1

\begin{tabular}{|c|c|c|c|c|c|}
\hline Model & $\begin{array}{c}\text { Unstandardized } \\
\text { Coefficients } \\
\text { B } \\
\end{array}$ & $\begin{array}{c}\text { Standardized } \\
\text { Coefficients } \\
\text { Std. Error } \\
\end{array}$ & Beta & $\mathbf{T}$ & Sig. \\
\hline 1 (Constant) & 1,005 & 0,496 & & 2,024 & 0,048 \\
\hline Kep. Transformasional & 0,567 & 0,113 & 0,564 & 5,025 & 0,000 \\
\hline
\end{tabular}

Sumber: Data diolah, 2019

Variabel kepemimpinan transformasional memiliki nilai koefisien regresi positif. Nilai signifikansi uji $\mathrm{t}$ dari variabel kepemimpinan transformasional tidak melebihi 0,05 . Niali $R$ Square dari variabel kepemimpinan transformasional adalah 0,319 yang berarti sebesar 3,19 persen variasi komitmen organisasional dipengaruhi oleh variasi kepemimpinan transformasional, sedangkan sisanya sebesar 68,1 persen, variabel lain yang tidak digunakan dalam model penelitian ini.

Tabel 14.

Hasil Analisis Jalur 2

\begin{tabular}{|c|c|c|c|c|c|}
\hline Model & $\begin{array}{c}\text { Unstandardized } \\
\text { Coefficients } \\
\text { B } \\
\end{array}$ & $\begin{array}{c}\text { Standardized } \\
\text { Coefficients } \\
\text { Std. Error } \\
\end{array}$ & Beta & $\mathbf{T}$ & Sig. \\
\hline 1 (Constan) & 1,399 & 0,358 & & 3,909 & 0,000 \\
\hline Kep. Transformasional & 0,303 & 0,095 & 0,378 & 3,184 & 0,002 \\
\hline Komitmen Org & 0,329 & 0,095 & 0.413 & 3,477 & 0,001 \\
\hline
\end{tabular}

Setiap variabel bebas yang telah diuji memiliki nilai koefisien positif. nilai signifikansi uji t dari setiap variabel bebas yang telah diuji kurang dari 0,05. Nilainilai hasil dari analisis jalur 2 memiliki arti bahwa variabel-variabel bebas yang telah diuji tersebut memiliki hubungan positif pada variabel terikat. Niali $R$ Square dari variabel OCB adalah 0,490 yang berarti sebesar 0,490 persen variasi OCB dipengaruhi oleh variasi kepemimpinan transformasional dan komitmen organisasional sedangkan sisanya sebesar 51 persen, variabel lain yang tidak digunakan dalam model penelitian ini.

Setelah dilakukan perhitungan untk menemukann pengaruh error (Pei) dan diapatkan Pei 1 yaitu 0,825 serta Pei2 yaitu 0,714 . Didapatkan juga nilai determinasi yaitu 0,654. Nilai 0,654 ini memiliki arti yaitu variasi kepemimpinan dan komitmen organisasional memiliki pengaruh terhadap variasi OCB sebesar 65,4 persen dan 34,6 persen sisanya dijelaskan oleh variabel lain yang tidak digunakan dalam model penelitian ini.

Nilai signifikansi sebesar 0,000 didapat dari hasil analisis pengaruh kepemimpinan transformasional pada komitmen organisasional. Dari hasil analisis tersebut didapatkan juga keofisien beta sebesar 0,564. Nilai signifikansi yang didapatkan yaitu 0,000 memiliki nilai yang lebih rendah dari 0,05 . Karena nilai signifikansi yang lebih rendah dari 0,05 maka $\mathrm{H}_{0}$ ditolak dan $\mathrm{H}_{1}$ diterima. Berdasarkan hasil uji hipotesis ditemukan adanya pengaruh yang positif dari kepemimpinan transformasional pada komitmen organisasional pada Dinas 
Koperasi dan UKM Provinsi Bali. Pengaruh positif disini berarti ketika pemimpin organisasi mampu menerapkan gaya kepemimpinan transformasional dengan baik yaitu mampu memberikan motivasi kepada anggota yang dipimpinnya, semakin baik dalam memberikan perhatian pada anggota organisasi dan dapat meningkatkan kreatifitas anggota organisasi maka hal tersebut akan berdampak pada meningkatnya komitmen dari pegawai pada organisasi tempatnya bekerja.

Penelitian ini dilandasi oleh Teori Pertukaran Sosial atau Social Exchange Theory. Teori ini pertama kali ditemukan oleh Blau pada tahun 1964. Komitmen organisasional akan terwujud ketika pegawai merasakan suatu pengaruh positif terhadap dirinya ketika bekerja di suatu organisasi. Komitmen organisasional merupakan salah satu feedback yang diberikan oleh pegawai kepada organisasi karena pengaruh positif yang dirasakan oleh pegawai tersebut. Hasil penelitian ini mendukung beberapa penelitian yang dilakukan oleh Taner et al. (2015), Faharani et al. (2011), Lee (2010), Ismail et al. (2011), dan Suryaningsih et al. (2017) dalam penelitian-penelitian yang dilakukan yang mengangkat topik serupa menemukan bahwa terdapat hubungan yang positif antara kepemimpinan transformasional pada komitmen organisasional.

Nilai signifikansi sebesar 0,002 didapat dari hasil analisis pengaruh kepemimpinan transformasional pada OCB. Dari hasil analisis tersebut didapatkan juga keofisien beta sebesar 0,378 . Nilai signifikansi yang didapatkan yaitu 0,002 memiliki nilai yang lebih rendah dari 0,05 . Karena nilai signifikansi yang lebih rendah dari 0,05 maka $\mathrm{H}_{0}$ ditolak dan $\mathrm{H}_{2}$ diterima. Berdasarkan hasil uji hipotesis ditemukan adanya pengaruh yang positif dari Kepemimpinan Transformasional pada $O C B$ pada Dinas Koperasi dan UKM Provinsi Bali. Pengaruh positif disini berarti ketika pemimpin mampu memeparkan tujuan organisasi secara jelas, mampu memberikan dorongan kepada anggota organisasi dan mampu merangsan kreatifitas dari anggota organisasi maka keberhasilan tersebut akan berdampak pada timbulnya perilaku OCB yang dilakukan oleh anggota organisasi tanpa adanya paksaan. Ketika individu memiliki keinginan untuk membuat reputasi organisasi tempat dia bekerja dan bersedua berperilaku OCB maka individu tersebut merasa dengan berperilaku OCB maka ada nilai-nilai positif yang akan didapatkan oleh individu tersebut. Hubungan ini dijelaskan oleh teori pertukaran social (Chiang \& Hsieh, 2012). Pertukaran sosial dapat terjadi ketika pegawai dan organisasi dapat memberikan suatu hal yang didasari pada kepercayaan melalui komitmen organisasional pada karyawan/ pegawai (Fung et al., 2012).Karyawan ketika melaksanakan tugasnya dengan baik tanpa adanya paksaan dan bekerja dengan tulus, perilaku tersebut disebut dengan organizational citizenship behavior atau OCB (Suryanatha \& Ardana, 2014). OCB timbul dari diri pekerja itu sendiri dan bukan dari jobdesk yang dimilikinya (Al-Zu'bi, 2011). Ketika organisasi memberikan feedback yang dianggap sesuai oleh pegawai, maka pegawai tersebut akan lebih mungkin berperilaku ekstra. Hasil penelitian ini mendukung temuan dari Malik et al. (2016), Yohana (2017), Lian \& Tui (2012), Zabihi \& Hashemzeh (2012), Rahmi (2014) dalam penelitian-penelitia yang dilakukan dengan menggunakan variabel yang sama menemukan adanya hubungan positif dari kepemimpinan transformasional pada OCB. 
Nilai signifikansi sebesar 0,001 didapat dari hasil analisis pengaruh komitmen organisasional pada OCB. Dari hasil analisis tersebut didapatkan juga keofisien beta sebesar 0,413 . Nilai signifikansi yang didapatkan yaitu 0,002 memiliki nilai yang lebih rendah dari 0,05 . Karena nilai signifikansi yang lebih rendah dari 0,05 maka $\mathrm{H}_{0}$ ditolak dan $\mathrm{H}_{3}$ diterima. Berdasarkan hasil uji hipotesis ditemukan adanya pengaruh yang positif dari komitmen organisasional pada $O C B$ pada Dinas Koperasi dan UKM Provinsi Bali. Hal ini memiliki makna bahwa pegawai yang memiliki komitmen organisasional yang tinggi akan dengan sendirinya menimbulkan Perilaku $O C B$ pada pegawai, karena pegawai yang merasa ikut memiliki organisasi dan bersedia dilibatkan dalam kegiatan organisasi akan bersedia melakukan pekerjaan melebihi tugas-tugas yang diberikan. Hubungan ini didukung oleh teori pertukaran sosial yang berarti bahwa ketika pegawai telah memiliki komitmen pada organisasi maka akan sendirinya berperilaku lebih dalam organisasi. Penelitian yang dilakukan oleh Sani (2013), Sahertian \& Soetjipto (2011), Han et al. (2016), Suparta et al. (2013), dan Bakan et al. (2013) menemukan hasil yang sama yaitu ditemukan adanya hubungan positif antara variabel komitmen organisasional terhadap OCB.

Tabel 15.

Pengaruh Langsung dan Pengaruh Tidak Langsung serta Pengaruh Total Kepemimpinan Transformasional (X), Komitmen Organisasional (M), dan Organizational Citizenship Behavior (Y)

\begin{tabular}{cccc}
\hline $\begin{array}{c}\text { Pengaruh } \\
\text { Variabel }\end{array}$ & $\begin{array}{c}\text { Pengaruh } \\
\text { Langsung }\end{array}$ & $\begin{array}{c}\text { Pengaruh Tidak Langsung Melalui } \\
\text { Komitmen Organisasional } \\
(\mathbf{M})(\boldsymbol{\beta 1} \mathbf{x} \boldsymbol{\beta})\end{array}$ & $\begin{array}{c}\text { Pengaruh } \\
\text { Total }\end{array}$ \\
\hline $\mathrm{X} \rightarrow \mathrm{M}$ & 0,564 & - & 0,564 \\
$\mathrm{X} \rightarrow \mathrm{Y}$ & 0,378 & 0,232 & 0,610 \\
$\mathrm{M} \rightarrow \mathrm{Y}$ & 0,413 & - & 0,413 \\
\hline
\end{tabular}

Sumber: Data diolah, 2019

Penghitungan variabel mediasi menggunakan statistik uji. Uji sobel dihitung dengan rumus dibawah ini:

$$
\begin{aligned}
& \left.\left.\mathrm{Z}=\frac{a b}{\sqrt{\mathrm{a}^{2} \mathrm{~S}_{\mathrm{b}}{ }^{2}+\mathrm{b}^{2} \mathrm{~S}_{\mathrm{a}}{ }^{2}+\mathrm{S}_{\mathrm{a}}{ }^{2} \mathrm{~S}_{\mathrm{b}}^{2}}}\right)\right) \ldots \ldots \\
& \mathrm{Sig}=(1-\operatorname{NORMDIST}(\mathrm{Z}))
\end{aligned}
$$

Keterangan:

$$
\begin{aligned}
& \mathrm{a}=0,564 \\
& \mathrm{~S}_{\mathrm{a}}=0,113 \\
& \mathrm{~b}=0,413 \\
& \mathrm{~s} \mathrm{~b}=0,095
\end{aligned}
$$

Tabel 16.

Hasil Uji Sobel

\begin{tabular}{cc}
\hline Nilai $\mathbf{Z}$ & Sig \\
\hline 3,2414 & 0,0012 \\
\hline Sumber: Data diolah, 2019 &
\end{tabular}

Sumber: Data diolah, 2019 
Setelah dilakukan uji sobel didapatkan hasil bahwa nilai $\mathrm{Z}$ hitung yaitu 3,2414. Nilai 3,2414 ini melebihi 1,96 dengan nilai signifikansi yaitu 0,0012 dimana lebih kecil dari 0,05. Kesimpulan hari hasil uji sobel yang telah dilakukan adalah komitmen organisasional variabel yang memediasi pengaruh kepemimpinan transformasional terhadap $O C B$ pada Dinas Koperasi dan UKM Provinsi Bali atau

Hasil uji menunjukan bahwa nilai $Z$ hitung sebesar 3,2414> 1,96 dengan nilai signifikansi $0,0012<0,05$, yang artinya komitmen organisasional merupakan variabel yang memediasi pengaruh kepemimpinan transformasional terhadap OCB pada Dinas Koperasi dan UKM Provinsi Bali. Pengujian sebelumnya menunjukkan pengaruh positif dan signifikan pada pengaruh kepemimpinan transformasional terhadap komitmen organisasional, kepemimpinan transformasional terhadap $O C B$ dan komitmen organisasional terhadap $O C B$, sehingga dapat disimpulkan bahwa komitmen organisasional secara parsial memediasi pengaruh kepemimpinan transformasional terhadap $O C B$. Hubungan ini didukung oleh teori pertukaran sosial yang berarti bahwa ketika pemimpin dengan gaya kepemimpinan transformasional mampu meningkatkan komitmen pada pegawai maka dengan sendirinya akan timbul perilaku $O C B$.

Penelitian ini mendukung beberapa hasil penelitian sebelumnya yang dilakukan oleh Truckenbrodt (2000) dalam penelitian yang dilakukannya menemukan bahwa terdapat hubungan antara pemimpin transformasional; subordinat penyelia dan komitmen organisasional bawahan; dan OCB. Menurut Wang (2006), gaya kepemimpinan transformasional dan komitmen organisasional secara positifmempengaruhiOCB pegawai. Dalam sebuah penelitian yang dilakukan oleh Chi et al. (2007), hasil menunjukkan bahwa komitmen organisasi sepenuhnya memediasi hubungan antara gaya kepemimpinan terhadap $O C B$.

Implikasi hasil penelitian ini memfokuskan pada kegunaan dan manfaat dari hasil penelitian untuk meningkatkan perilaku OCB pada pegawai Dinas Koperasi dan UKM Provinsi Bali melalui kepemimpinan transformasional dan komitmen organiasional. Implikasi pertama yaitu diperoleh hasil bahwa Dinas Koperasi dan UKM Provinsi Bali menerapkan gaya kepemimpinan transformasional dengan baik, dimana pemimpin mampu untuk dapat menimbulkan inovasi dan kreatifitas bawahan dalam melakukan pekerjaan dan pemimpin mampu memberikan dorongan kepada pegawai agar semangat dalam bekerja sehingga pegawai mampu meningkatkan kontribusi dalam kesuksesan organisasi.

Implikasi yang kedua yaitu diperoleh hasil bahwa tingginya komitmen organisasional pada Dinas Koperasi dan UKM Provinsi Bali, dimana pegawai bersedia dilibatkan dalam kegiatan kerja demi kepentingan organisasi sehingga akan timbul perilaku $O C B$ pada pegawai. Implikasi yang ketiga yaitu diperoleh hasil bahwa tingginya OCB pada Dinas Koperasi dan UKM Provinsi Bali, dimana pegawaitidak memberikan isu - isu yang dapat menjatuhkan karyawan lain dan karyawan bersedia membantu rekan kerja yang memiliki beban kerja lebih dengan sukarela sehingga pekerjaan tidak akan terganggu dengan adanya isu-isu negatif dan pekerjaan akan lebih mudah dan cepat terselesaikan dengan adanya bantuan antar sesama rekan kerja.

Implikasi teoritis yang diperoleh dari penelitian ini adalah kepemimpinan transformasional dan komitmen organisasional secara positif dan signifikan 
mempengaruhi $O C B$. Komitmen organisasional merupakan variabel mediasi parsial karena mampu menunjukkan bahwa kepemimpinan transformasional dan komitmen organisasional sebagai faktor - faktor yang mempengaruhi $O C B$. Hasil penelitian ini memberi dukungan empiris dan dinyatakan dapat memperkuat hasil-hasil studi terdahulu.

\section{SIMPULAN}

Kepemimpinan transformasional berpengaruh positif pada komitmen organisasional pada Dinas Koperasi dan UKM Provinsi Bali, dimana semakin baik penerapan gaya kepemimpinan transformasional pada seorang pemimpin maka akan semakin tinggi komitmen pegawai terhadap organisasinya. Kepemimpinan transformasional berpengaruh positif pada $O C B$ pada Dinas Koperasi dan UKM Provinsi Bali. Hal ini memiliki makna bahwa seorang pemimpin yang mampu untuk dapat menimbulkan inovasi dan kreativitas bawahan dalam melakukan pekerjaan akan menimbulkan perilaku $O C B$ pada pegawai.

Komitmen organisasional berpengaruh positif dan signifikan terhadap $O C B$ pada Dinas Koperasi dan UKM Provinsi Bali. Hal ini memiliki makna bahwa pegawai yang memiliki komitmen organisasional yang tinggi akan dengan sendirinya menimbulkan perilaku $O C B$ pada pegawai, karena pegawai yang bersedia dilibatkan dalam kegiatan perusahaan akan bersedia melakukan pekerjaan melebihi tugas-tugas dan tanggung jawab yang diberikan. Komitmen organisasional merupakan variabel yang memediasi pengaruh kepemimpinan transformasional terhadap $O C B$ pada Dinas Koperasi dan UKM Provinsi Bali atau dengan kata lain kepemimpinan transformasional berpengaruh secara tidak langsung terhadap $O C B$ melalui komitmen organisasional.

Saran yang diberikan dalam penelitian ini, berdasarkan hasil analisis dan pembahasan yang telah dipaparkan adalah sebagai berikut.Upaya meningkatkan perilaku $O C B$ pada karyawan, perusahaan harus mampu membuat karyawannya melaksanakan tugas melebihi tugas yang diberikan dengan cara membuat lingkungan dan suasana kerja di sekitar pegawai menyenangkan sehingga pegawai betah untuk bekerja. Pemimpin pada Dinas Koperasi dan UKM Provinsi Bali hendaknya mampu untuk memperhatikan kebutuhan bawahan dengan cara pemimpin harus mampu mengetahui apa yang dibutuhkan oleh bawahanya dalam menyelesaikan pekerjaan yang diberikan. Upaya meningkatkan komitmen organisasional pada pegawai, organisasi harus mampu membuat pegawainya merasa kehidupannya akan terganggu apabila meninggalkan organisasi dengan cara organisasi harus mampu menciptakan interaksi yang baik antar sesama pegawai, antara pegawai dan atasanya, hal ini perlu dilakukan karena interaksi yang baik akan menyebabkan pegawai nyaman dan betah pada sebuah organisasi dan hal lain yang bisa dilakukan memberikan apresiasi kepada pegawai atas apa yang telah dikerjakannya.

\section{REFERENSI}

Al-Zu'bi, H. A. (2011). Organizational Citizenship Behavior and Impacts Knowledge Sharing: An Empirical Study. International Business Research, 4(3), 221-227. 
Bakan, I., Buyukbese, T., Frsahan, B., \& Kefe., I. (2013). The Effect of Organizational Commitmen on Women Employees Organizational Citizenship Behavior. Indian Journal of Applied Research, 3(2), 202-204.

Bass, B. M., Avolio, B. J., Jung, D. I., \& Berson, Y. (2003). Predicting unit performance by assessing transformational and transactional leadership. Journal of Applied Psychology., 88(2), 207-21.

Chi, H., Tsai, H., \& Chang, P. (2007). Investigating the relationship among leadership styles, emotional intelligence and organization commitment on job performance: A study of salespeople in Thailand. The Journal of Human Resource and Adult Learning, 3(2), 199-212.

Chiang, C. F., \& Hsieh, T. S. (2012). The Impact Of Perceived Organizational Suport And Psyhchological Empowerment On Job Performance: The Mediating Effect Of Organizational Citizenship behavior. International Journal Of Hospitality Management, 31(1), 180-190.

Faharani, M., Taghadosi, M., \& Behboudi, M. (2011). An Exploration of the Relationship between Transformational Leadership and Organizational Commitment: The Moderating Effect of Emotional Intelligence: Case Study in Iran. International Business Research., 4(4), 211-217.

Foote, D. A., \& Tang, T. L.-P. (2008). Job satisfactionand organizational citizenship behavior (OCB) Does team commitment make a difference in selfdirectedteams?. Management Decision., 46(6), 933-947.

Fung, N. S., Ahmad, A., \& Omar, Z. (2012). Work-Family Enrichment: It's Mediating Role in the Relationships between Dispositional Factors and Job Satisfaction. International Journal of Academic Research in Business and Social Sciences, 2(11).

Griffin, R. W. (2008). Management. USA.: Mc-Graw Hil.

Han, S. H., Seo, G., Li, J., \& Yoon, S. W. (2016). The mediating effect of organizational commitment and employee empowerment: how transformational leadership impacts employee knowledge sharing intention. Human Resource Development International, 19(2), 98-115.

Huang, C.-C., Sing, C., \& Tien, M. (2012). A Multidimensional Analysis of Ethical Climate, Job Satisfaction, Organizational Commitment and Organizational Citizenship Behavior. Nursing Ethics Journal, 19(4), 513-529.

Ismail, A., Mohamed, H., Sulaiman, A. Z., Mohamad, M. H., \& Yusuf, M. H. (2011). An Empirical Study of the Relationship between Transformational Leadership, Empowerment and Organizational Commitment,. Business and 
Economics Research Journal, 2(1), 89-107.

Kaihatu, T. S., \& Rini, W. A. (2007). "Kepemimpinan Transformasional dan Pengaruhnya terhadap Kualitas Kehidupan Kerja, Komitmen Organisasi, dan Perilaku Ekstra Peran: Studi pada Guru-Guru SMU di Kota Surabaya",. Jurnal Manajemen Dan Kewirausahan, Universitas Kristen Petra, 98(1), 4961.

Karim, F., \& Rehman, O. (2012). Impact of Job Satisfaction, Perceived Organizational Justice and Employee Empowerment on Organizational Commitment in Semi-Government Organizations of Pakistan. Journal of Business Studies Quarterly, 3(4), 92-104.

Kumar, K., Bakhshi, A., \& Rani, E. (2009). Linking the ,Big Five Personality Domains to Organizational Citizenship Behavior,. International Journal of Psychological Studies., 1(2), 73-81.

Kumar, R., Charles, R., \& Peter, Y. (2011). A Study on Turnover intention in Fast Food Industry: Employees' Fit to the Organizational Culture and the Important of their Commitment. International Journal of Academic Research in Business and Social Sciences, 2(5), 9-42.

Lamidi. (2008). Pengaruh Kepemimpinan Transformasional Terhadap Organization Citizenship Behavior: Dengan Variabel Intervening Komitmen Organisasional. Jurnal Ekonomi Dan Kewirausahaan, 8(1), 25 - 37.

Lee, H. W. (2010). Relationship between leadership style and organizational commitment. Operating Management Review., 6(1), 87-95.

Lian, L. K., \& Tui, L. G. (2012). Leadership Styles and Organizational Citizenship Behavior: The Mediating Effect of Subordinates' Compotence and Downward Influence Tactics. Journal of Applied Busines and Economics, 13(2), 59-96.

Luthans, \& Frens. (2006). Perilaku Organisasi (10th ed.). Yogyakarta: Andi.

Maharani, V., Troena, E. A., \& Noermijati. (2013). Organizational citizenship behavior role in mediating the effect of transformational leadership, job satisfaction on employee performance: Studies in PT. Bank Syariah Mandiri Malang East Java. International Journal of Business and Management., 8(17), 1-12.

Malik, S. Z., Saleem, M., \& Naheem, R. (2016). Effect of Leadership Styleon Organizational Citizenship Behaviourin Employee of Telecom Sector in Pakistan. Economic and Social Review, 54(2), 385-406. 
Meyer, J., \& Allen, N. (1991). "A three-component conceptualization of organizational commitment." Human Resource Management Review., 1(1), $61-98$.

Mira, W. (2012). Pengaruh Servant Leadership terhadap Komitmen Organisasi dan Organization Citizenship Behavior. Jurnal Manajemen, 11(2), 189.

Organ, D. W., Podsakoff, P. M., \& MacKenzie, S. B. (2006). Organizational Citizenship Behavior. Its Nature, Antecendants, and Consequences. Sage Publicaton.

Ortiz, M. Z., Rosario, E., Marquez, E., \& Gruñeiro, P. C. (2015). "Relationship between organizational commitments and organizational citizenship behaviour in a sample of private banking employees",. International Journal of Sociology and Social Policy., 35(1), 91 - 106.

Priansa, D. (2014). Perencanaandan Pengembangan SDM. Bandung: Alfabeta.

Rahmatun, T. A., \& Kistyanto, A. (2014). Pengaruh gaya kepemimpinan transformasional dan komitmen organisasi terhadap organizational citizenship behaviour. Jurnal Ilmu Manajemen, 2(1), 37-49.

Rahmi, B. M. (2014). Pengaruh Kepemimpinan Transformasional Terhadap Organizational Citizenship Behavior Dand Komitmen Organisasi Dengan Mediasi Kepuasan Kerja (Studi pada Guru Tetap SMA Negeri di Kabupaten Lombok Timur). E-Jurnal Manajemen Universitas Udayana, 3(2), 331-350.

Robins, S. P., \& Judge, T. A. (2008). Organizational Behavior. US: Prentice Hall.

Rorimpandey, L. (2013). Gaya Kepemimpinan Transpormasional, Transaksional, .Situasional, Pelayanan dan Autentik Terhadap Kinerja Pegawai Keluraha Di kecamatan Bunaken Kota Manado. Jurnal EMBA, 1(4), 89-90.

Sahertian, P., \& Soetjipto, B. E. (2011). Improving Employee's Organizational Commitment, Self-Efficacy, and Organizational Citizenship Behavior Through the Implementation of Task Oriented and Relationship Oriented Leadership Behavior. The Business Review., 17(2), 48-60.

Sani, A. (2013). Role of Procedural Justice, Organizational Commitment andJob Satisfaction on Job Performance: The Mediating Effects ofOrganizational Citizenship Behavior. International Journal of Businessand Management., $8(15), 57-67$.

Sesen, H., \& Basim, N. H. (2012). Impact of satisfaction and commitment on teachers' organizational citizenship. Educational Psychology, 32(4), 475491. 
Shweta, J., \& Srirang, J. (2010). Determinants of Organizational Citizenshi Behavior: A Review of Literature,. Journal of Management and Public Policy., 1(2), 27-36.

Sugiyono. (2017). Metodologi Penelitian Kuantitatif, Kualitatif, dan R\&D. Bandung: CV Alfabeta.

Suparta, P. J., Supartha, G., \& Utama., W. M. (2013). Pengaruh Moral Karyawan dan Komitmen Organisasi Terhadap Organizational Citizenship Behavior dan Kinerja Individual Karyawan (Studi Kasus di Rama Beach Resort \& Villas). E-Jurnal Ekonomi Dan Bisnis Universitas Udayana., 2(11), 85-92.

Suryanatha, A., \& Ardana, K. (2014). Pengaruh Kepemimpinan Transformasional dan Komitmen Organisasi terhadap Kepuasan Kerja Karyawan dan OCB pada Baleka Resort Hotel \& Spa Legian. E-Jurnal Manajemen Universitas Udayana, 3(4), 1155-1170.

Suryaningsih, T., Cahyoadi, B., \& Madhuni., N. I. (2017). Pengaruh Kepemimpinan Transformasional Terhadap Komitmen Organisasi Sebagai Upaya Peningkatan Keunggulan Bersaing Salesman Sepeda Motor Di Wilayah Kabupaten Tulungagung. Jurnal Pendidikan Ekonomi.

Suyitno, A. S., \& Utomo., H. (2017). Pengaruh Gaya Kepemimpinan Transformasional, Kompensasi Dan Budaya Organisasi Terhadap Produktivitas Kerja Karyawan (Studi Kasus Pada Perhimpunan BMT Indonesia di Kabupaten Semarang). Jurnal Ilmiah Among Makarti, 9(8), 5779.

Taner, B., Turhan., M., Helvaci, I., \& Koprulu., O. (2015). The Effect of the Leadership Perception and Organizational Juctice on Organizational Commitment: A Research in State University. International Review of Management and Marketing, 5(3), 180-194.

Truckenbrodt, Y. B. (2000). "The Relationship Between Leader-Member Exchange and Commitment and Organizational Citizenship Behavior",. Journal: Acquisition Review Quarterly-Summer 2000, 233-244.

Wang, C. (2006). Applying structural equation modeling to study the influence of leadership styles, job satisfaction, organization commitment and job performance: An empirical study of real estate agents in Taoyuan area. National Donghwa University, Taiwan, 36(2), 37-43.

Yang, M.-L. (2012). Transformational Leadership and Taiwanese Public Relations Practitioner' Job Satisfaction and Organizational Commitment. Social Behavior and Personality, 40(1), 31-46. 
E-Jurnal Manajemen, Vol. 8, No. 11, 2019 : 6887-6909

Yohana, C. (2017). The effect of leadership, organizational support and organizational citizenship behavior on service quality. Journal Problems and Perspectives in Management, 15(2).

Zabihi, M., \& Hashemzehi, R. (2012). The relationship between leadership styles and organizational citizenship behavior. African Journal of Business Management., 6(9), 3310-3319. 